\title{
Study of gas supply way and velocity chosen during the process of MPCVD diamond
}

\author{
XiaoJing $\mathrm{Li}^{\mathrm{a}^{*}}$,ShunQi Zheng ${ }^{\mathrm{b}}$, Yangsheng Zheng ${ }^{\mathrm{c}}$, Wenqing Wang ${ }^{\mathrm{d}}$, \\ Renna $\mathrm{Wu}^{\mathrm{e}}$, Rui li
}

The Ningbo branch of Ordnance Science institute of China, Ningbo 315103, China

aemail:happybuaa@126.com , bemail:nbkjhz@163.com, 'email:794557909@qq.com ,

demail:447691443@qq.com eemail:510838140@qq.com

Keywords: Microwave plasma chemical vapor deposition (MPCVD), Gas supply, Velocity

\begin{abstract}
The Microwave plasma chemical vapor deposition (MPCVD) method was used to make diamond film in this paper. The influence of working gas supply mode and velocity were investigated using numerical simulation method. The distribution of gas flow rate at two different gas supply modes was analyzed by software Fluent. The results showed that, the gas supply mode whose gas inlet is a hole located at the bottom of the plunger is a better choice for the formation of uniform film, gas velocity is chosen between $5 \mathrm{~m} / \mathrm{s}$ to $10 \mathrm{~m} / \mathrm{s}$ 。
\end{abstract}

\section{Introduction}

Among the various techniques that depositing diamond films, microwave plasma chemical vapor deposition (MPCVD) has gained more attention due to its advantages, such as, no pollution from electrodes, high density of the plasma, well controlled microstructures as well as high quality of deposited diamond films.

During the last 20 years, many types of MPCVD devices have been developed, including the quartz tube type [1], the quartz bell jar type [2], the cylindrical type [3], the ellipsoidal cavity type [4] and the non-cylindrical cavity type [5]. In all these MPCVD reactors, the microwave cavities are the most important components. Design and improvement of the cavities are the key issue for the development of the MPCVD techniques.

Recently, with the development of computer science, numerical simulation method was used for the design and optimization of the structure of MPCVD devices [6-10]. Research on the gas inlet ways and the velocity optimization were carried out in this paper, the research results will provide reference for the design and improvement of MPCVD device.

\section{Selection of supply path and velocity of working gas}

\section{MPCVD setup and gas supply.}

Fig. 1 shows schematically the cross-sectional view of MPCVD setup, it has been reported in the previous works [11]. The whole microwave plasma chemical vapor deposition system was analyzed by numerical simulation, which including microwave transmission part, coaxial conversion and microwave cavity. 


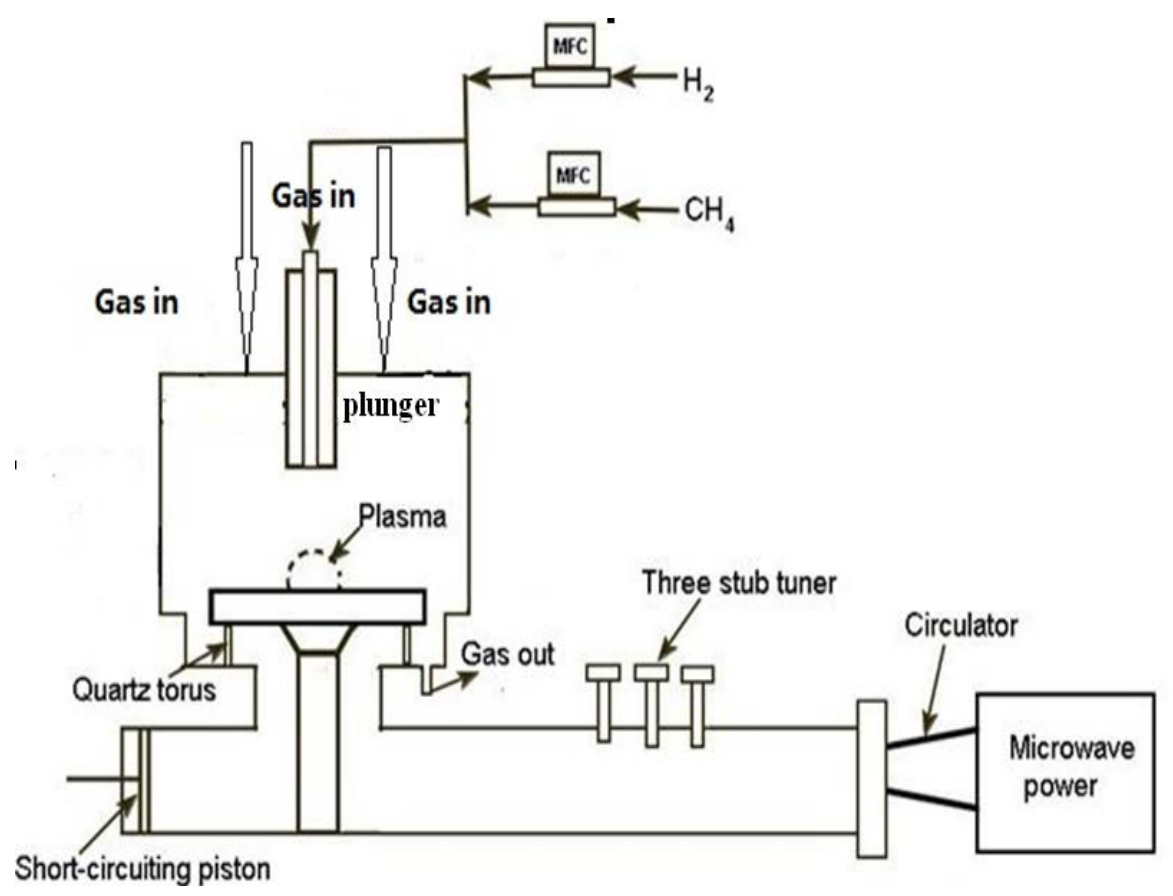

Fig.1The cross-sectional view of MPCVD setup

The working gas used in the experiment for diamond film deposition was pumped into the chamber through the top of the cavity. The working gas is a mixture of hydrogen $\left(\mathrm{H}_{2}\right)$ and methane $\left(\mathrm{CH}_{4}\right)$. Gas supply in different ways has great influence on the distribution of gas flow rate inside the microwave cavity. The working gas flow in the cavity was analyzed by software Fluent [12].

Two different gas supply modes were designed in this study, as is shown in Fig.3. In mode (I), the mixed working gas flowed into the chamber through the micro-holes on the top of the microwave cavity. The holes was arranged around the plunger, as the dashed line represents in Fig.2 (a) . In mode (II), the gas inlet is a hole located at the middle of the plunger (Fig.2 (b) ). In both mode (a) and mode (b), the inlet gas flow rate was assumed to be $1 \mathrm{~m} / \mathrm{s}, 2 \mathrm{~m} / \mathrm{s}, 5 \mathrm{~m} / \mathrm{s}, 10 \mathrm{~m} / \mathrm{s}$. The distribution of gas flow rate inside the cavity was simulated.
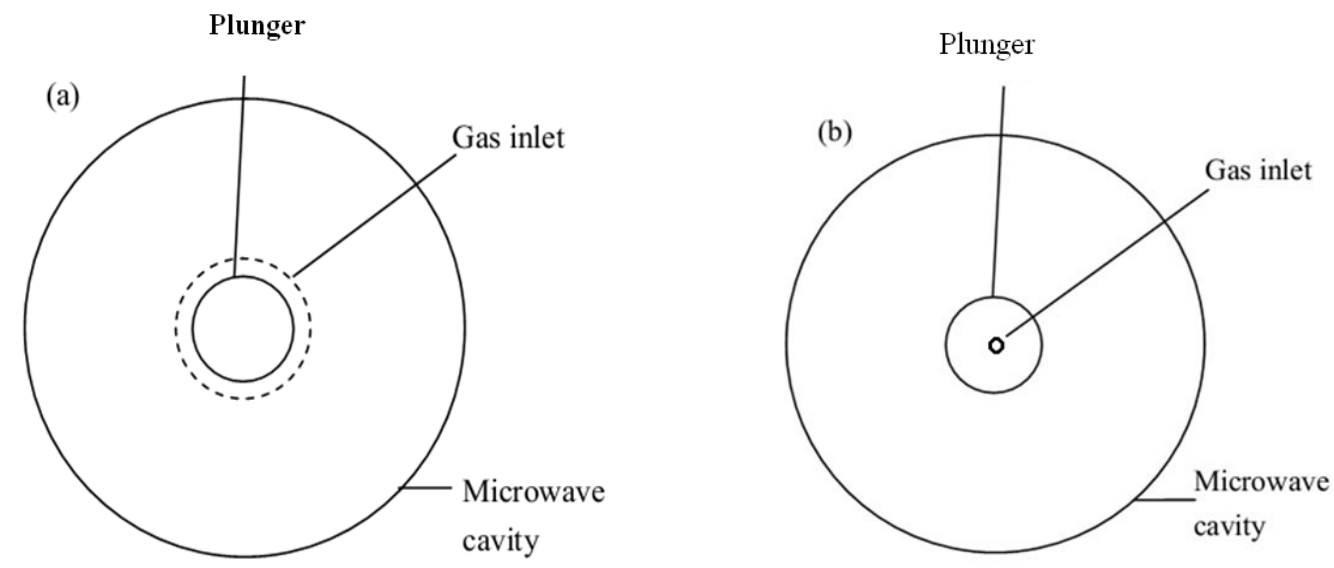

Fig.2 Two different gas supply mode: (a) mode (I) , (b) mode (II) 
Gas supply way in mode (I).

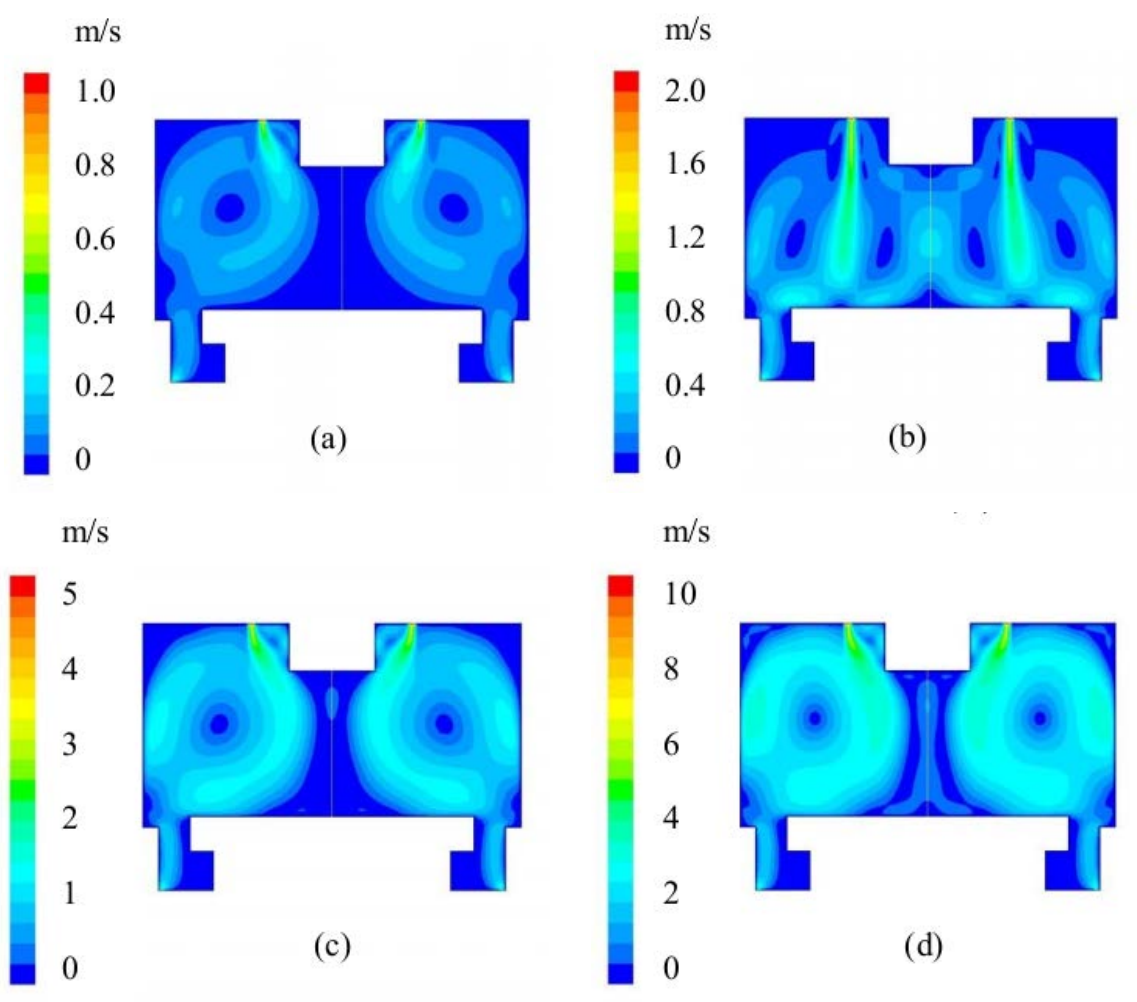

Fig.3 The distribution of gas flow rate inside the cavity in mode (I) with different inlet gas flow rate:
(a) $1 \mathrm{~m} / \mathrm{s}$
(b) $2 \mathrm{~m} / \mathrm{s}$
(c) $5 \mathrm{~m} / \mathrm{s}$
(d) $10 \mathrm{~m} / \mathrm{s}$.

It can be seen in the Fig.3 that in mode (I), the gas flow distribution varied with the change of inlet gas flow rate. When the inlet gas flow rate was $1 \mathrm{~m} / \mathrm{s}$ (Fig.3(a)), the gas flow over the substrate holder was very small, but it increased a lot when the inlet gas flow rate increased to $2 \mathrm{~m} / \mathrm{s}$. When the gas flow rate reach up to 5 to $10 \mathrm{~m} / \mathrm{s}$ Fig.3 (c), (d), the gas above the substrate presents the tendency of decrease, almost no gas flows through the center of it, which is not good for plasma excitation here.

Gas supply way in mode (II).

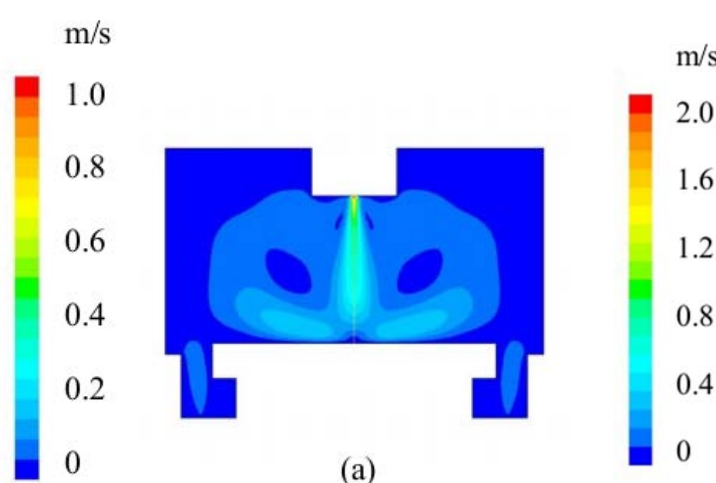

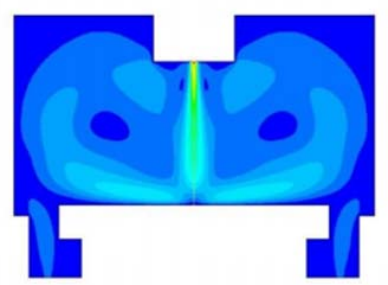

(b) 

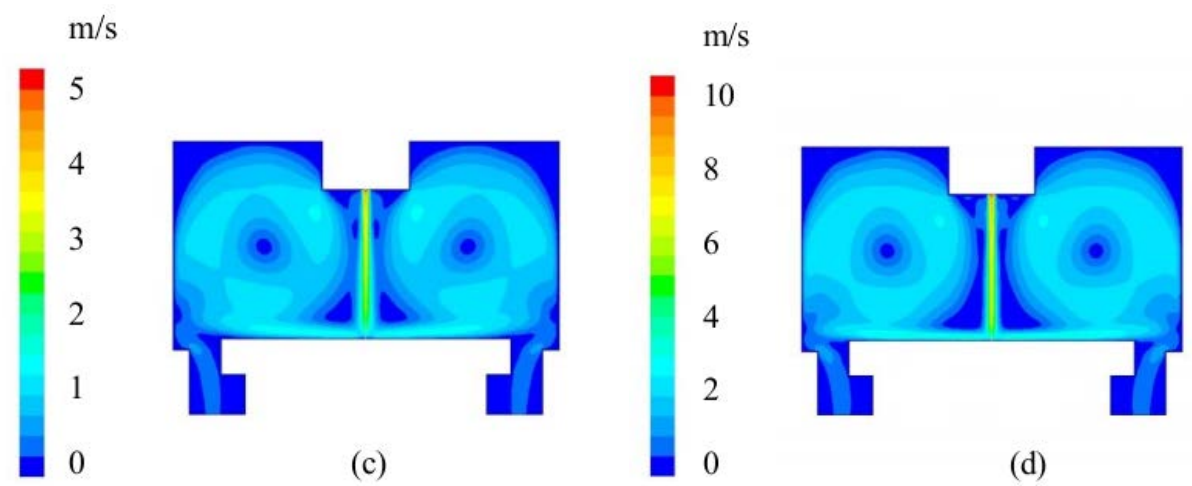

(c)

(d)

Fig.4 The distribution of gas flow rate inside the cavity in mode (II) with different inlet gas flow rate:
(a) $1 \mathrm{~m} / \mathrm{s}$
(b) $2 \mathrm{~m} / \mathrm{s}$ (c) $5 \mathrm{~m} / \mathrm{s}$
(d) $10 \mathrm{~m} / \mathrm{s}$.

Fig. 4 shows the distribution of gas flow rate inside the cavity in mode (II) with different inlet gas flow rate. In mode (II), most of the gas flow was distributed over the substrate when the inlet flow rate was low. With the increase of the inlet gas flow, the gas flow over the substrate became greater and uniform. as we know, the gas will be consumed when the plasma was ignited, so a uniform gas flow is needed to deposit a uniform film Both the inlet gas flow of $5 \mathrm{~m} / \mathrm{s}$ and $10 \mathrm{~m} / \mathrm{s}$ could ensure a homogeneous gas supply, but a lower flow rate could be controlled more easily, while a higher flow rate mean a higher deposit rate.

By comparing the simulation results, it could be concluded obviously that mode (II) is a better gas supply way. And the inlet flow rate could be chosen between $5 \mathrm{~m} / \mathrm{s}$ to $10 \mathrm{~m} / \mathrm{s}$.

\section{Experimental research}

The MPCVD diamond film experiment was carried out, in which the gas supply mode (II) was adopted, the inlet gas flow rate was $5 \mathrm{~m} / \mathrm{s}$. The deposition was conducted with the microwave input power of $5 \mathrm{kWand}$ a gas pressure of $15 \mathrm{kPa}$. The working gas was consisted of $99 \mathrm{vol} . \%$ hydrogen $\left(\mathrm{H}_{2}\right)$ and 1 vol.\% methane $\left(\mathrm{CH}_{4}\right)$. A silicon wafer with a diameter of 1.5 inch was used as the substrate. The whole deposition process lasted ten hours.

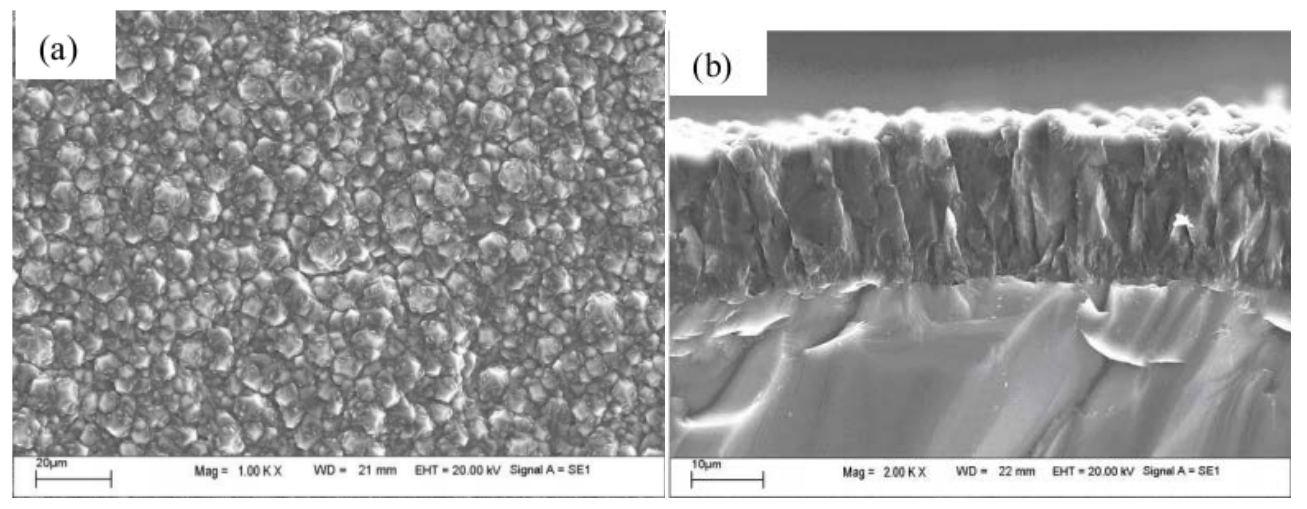

Fig.5 Surface (a) and cross section (b) morphology of a deposited diamond film

The Surface and cross section morphology was examined by SEM. Fig.5 (a) shows the surface morphology of a deposited diamond film. The surface diamond grains are in the micro size, and a lot of the grains is axial symmetry, which indicates that their grain grain orientation is close to (100).It can Fig.5 (b) shows the cross section morphology of the diamond film, the thickness of diamond film is about $20 \mu \mathrm{m}$. So the growth rate of the diamond film was about $2 \mu \mathrm{m} / \mathrm{h}$, and the depositing process appeared to be uniform. The results show that the diamond film can be perfectly produced using these process parameters. 


\section{Conclusions}

Based on numerical simulations, the supply way and inlet gas flow rate were optimized by numerical simulation method. Two different gas supply modes were designed in this study. In mode (I), the mixed working gas pumped into the chamber from micro-holes around the plunger .In mode (II), the gas inlet is a hole located at the middle of the plunger. The mode (II) is a better supply way, it is favorable for the formation of uniform film. And the proper inlet gas flow rate was $5-10 \mathrm{~m} / \mathrm{s}$. Experimental research was carried out, in which the supply mode (II) was adopted. The gas velocity is $5 \mathrm{~m} / \mathrm{s}$. Uniform diamond film could be deposited on substrates successfully using these process parameters.

\section{Acknowledgement}

This work was financially supported by the Natural Science Foundation of Zhejiang province grant No. LQ13F010002 and Public Project of Zhejiang Province under Grant No. 2014C31113. Additional Natural Science Foundation of Ningbo under Grant No. 2014A610012, which are gratefully acknowledged.

\section{References}

[1] M. Kamo, Y. Sato, S. Matsumoto, N. Setaka, J. Cryst. Growth 62 (1983) 642.

[2] P. Bachmann, D. Leers, H. Lydtin, Diamond Relat. Mater. 1 (1991) 1.

[3] P. Bachmann, Chem. Eng. News 67 (1989) 24.

[4] M. Funer, C. Wild, P. Koidl, Appl. Phys. Lett. 72 (1998) 1149.

[5] Seki Technotron Corp., http://www.sikitech.biz/.

[6] W. Tan, T.A. Grotjohn, Diamond Relat. Mater. 4 (1995) 1145.

[7] M. Funer , C. Wild, P. Koidl, Surf. Coat. Technol. 116-119 (1999) 853.

[8] F. Y. Wang, H. B. Guo, W. Z. Tang, Journal of synthetic crystals 37 (2008) 895.

[9] H. Yamada, A. Chayahara, Y. Mokuno, Shin-ichi Shikata, Diamond Relat. Mater. 17 (2008) 1062.

[10] F. Silva, X. Bonnin, J. Scharpf, A. Pasquarelli, Diamond Relat. Mater.19 (2010) 397.

[11] X.J. Li, W.Z. Tang, S.W. Yu, S.K. Zhang, G.C. Chen, F.X. Lu, Design of novel plasma reactor for diamond film deposition, Diamond and Related Materials,2011, 20 :480.

[12] zhanzhong Han, Jing Wang, Xiaoping Lan, FLUENT fluid simulation calculating examples and engineering application, Beijing Institute Technology Press ,Beijing,2004. 